\title{
Development of a Model Mutagenesis System for Snapdragon ${ }^{1}$
}

\author{
Zhaoyuan Lian, Heqiang Huo, Sandra Wilson, and Jianjun Chen ${ }^{2}$
}

\section{Introduction}

Snapdragon (Antirrhinum majus) has long been a popular perennial in the United States due to its unique flower shape with a range of striking colors (Huo and Chen 2018). Based on height, snapdragons typically fall into one of three categories: dwarf (6-15 inches), medium (1-2 feet), and tall (2-3 feet; Figure 1). These different heights allow a variety of uses. The dwarf varieties have a dense, bushy growth pattern, producing numerous flower spikes. On average, these grow 6-15 inches tall and are ideal for use in low borders or containers. Mid-sized varieties grow 1-2 feet tall and are typically used in borders (either alone or with other bedding plants) and sometimes as cut flowers. Tall varieties range anywhere from 2 to 3 feet in height (Gilman et al. 2018). The magnificent flowers with a wide range of petal colors atop the long green spikes make the tall variety a desirable cut flower for containers, bouquets, or gardens. Fresh-cut snapdragon sales increased 51.7\% from 2010 to 2015 and reached $\$ 12.93$ million, making the snapdragon a top ten fresh-cut flower in the United States (USDA 2016).

With their unique aesthetic attributes and versatility, snapdragons are also an important model system for genetics and molecular studies of various plant processes. For example, snapdragon pigmentation mutants produced by transposon (a type of mobile DNA) mutagenesis have provided researchers with a good way to study anthocyanin biosynthesis and aid plant breeders in developing new varieties with novel flower colors (Jackson et al. 1992). Furthermore, snapdragon has a mechanism by which transposable mutations can be regulated into active and inactive states through temperature control (Hashida et al. 2006). Advantages of this elegant transposon mutagenesis system and its connection to plant breeding are described below.

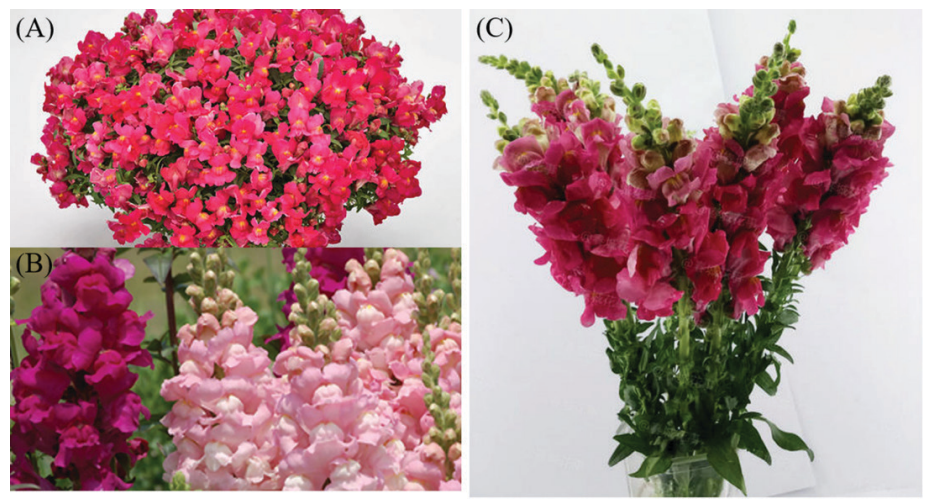

Figure 1. Different uses of snapdragons. (A) Dwarf snapdragon variety used for pot culture. (B) Medium snapdragon variety used as a landscape border. (C) Tall snapdragon variety used for cut flowers. Credits: Zhaoyuan Lian, UF/IFAS

\section{The Snapdragon "J12" Mutagenesis System}

Transposons are DNA elements that can move and insert themselves into new loci within a genome. Plant genomes

1. This document is ENH1320, one of a series of the Environmental Horticulture Department, UF/IFAS Extension. Original publication date August 2020. Visit the EDIS website at https://edis.ifas.ufl.edu for the currently supported version of this publication.

2. Zhaoyuan Lian, PhD candidate, Environmental Horticulture Department; Heqiang Huo, assistant professor, Environmental Horticulture Department, UF/IFAS Mid-Florida Research and Education Center; Sandra Wilson, professor, Environmental Horticulture Department; and Jianjun Chen, professor, Environmental Horticulture Department, UF/IFAS MREC; UF/IFAS Extension, Gainesville, FL 32611.

The Institute of Food and Agricultural Sciences (IFAS) is an Equal Opportunity Institution authorized to provide research, educational information and other services

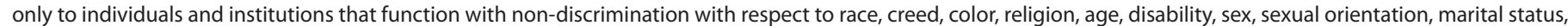

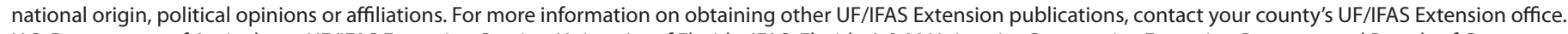
U.S. Department of Agriculture, UF/IFAS Extension Service, University of Florida, IFAS, Florida A \& M University Cooperative Extension Program, and Boards of County Commissioners Cooperating. Nick T. Place, dean for UF/IFAS Extension. 
contain a number of active transposons with the potential for gene disruption, chromosome breakage, and genome rearrangement. Several active transposons have been identified in snapdragon, including Tam3, which is of particular interest. Tam3 is a well-known transposon in snapdragon, whose transposition is strictly regulated by temperature. Activated only when plants are grown at low temperatures $\left(\leq 15^{\circ} \mathrm{C}\right)$ for more than 60 days, Tam 3 is strongly inhibited by high temperatures $\left(\geq 25^{\circ} \mathrm{C}\right)$ (Hashida et al. 2006). When activated in low temperatures, Tam 3 will move and insert into a new position in the snapdragon genome randomly, which can produce a variety of plant mutants. The unique snapdragon stock "JI2" (Pallida recurrens) containing a highly active Tam 3 causes flower color to change from red in the low temperature range $\left(\leq 15^{\circ} \mathrm{C}\right)$ to white in the high temperature range $\left(\geq 25^{\circ} \mathrm{C}\right)$ (Figure 2$)$. This serves as a visible marker to monitor the Tam 3 activity.
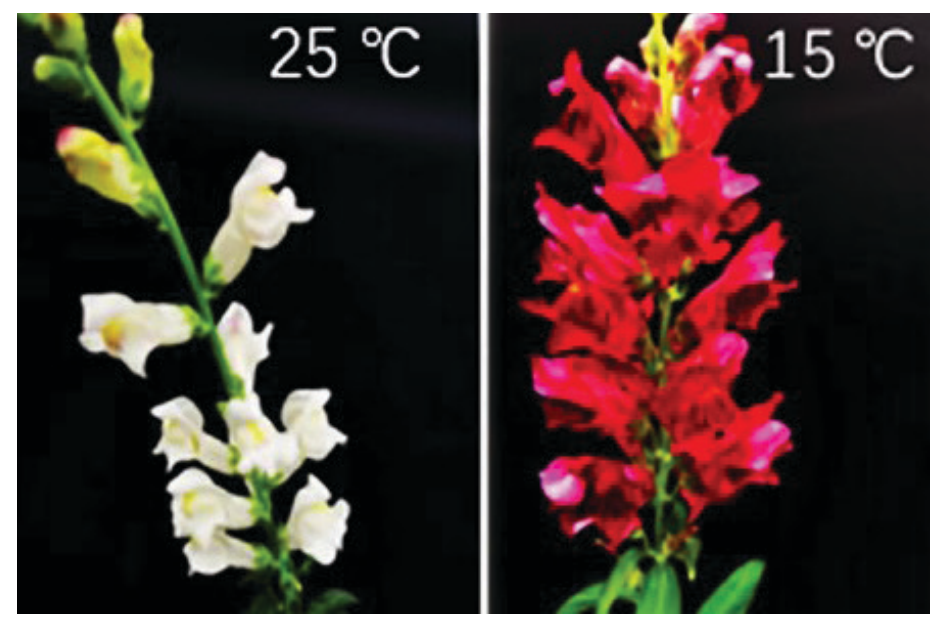

Figure 2. The flower color change of snapdragon "JI2" in different temperatures.

Credits: Zhaoyuan Lian, UF/IFAS

\section{Advantages of the Snapdragon "JI2" Mutagenesis System}

\section{Convenience}

For breeding with traditional mutagenesis, chemical mutagens such as ethyl methanesulfonate (EMS), methyl methanesulfonate (MMS), and diethyl sulfate (DES) or physical mutagens such as UV rays, $\mathrm{X}$-rays, and $\gamma$-rays are used to generate mutations. These chemicals and radiation instruments are hazardous and costly to use. Therefore, significant health and safety training must be completed. In addition, chemical/physical mutagenesis frequently creates deleterious mutations, requiring additional efforts to purify through backcrossing to the wild-type plants. Another key drawback of traditional mutagenesis is that it is extremely hard and time-consuming to develop molecular markers for utilizing these mutants as breeding materials, because a great number of random mutations will be created in each genome and be hard to detect. However, the Tam3 mutagenesis system is completely risk-free. No specific chemicals and instruments are needed in the entire mutagenesis process. A cooler room with an adjustable temperature to $15^{\circ} \mathrm{C}$ is the only required facility to activate Tam 3 transportation for mutagenesis.

\section{Non-GMO Varieties}

Unlike other model plant species such as Arabidopsis that heavily rely on T-DNA mutant libraries for functional characterization, mutant libraries created by random transpositions of temperature-dependent Tam 3 fall beyond the scope of USDA/EPA regulations. The availability of the whole genome and rapid sequencing technology advancement make it simpler to identify and characterize transposoninduced mutations, which in turn can be developed for molecular markers. More importantly, these mutants can be directly used as breeding lines for the development of novel snapdragon varieties. Year-round high temperatures, especially in Florida, will strongly inhibit the activation of Tam3, so the new variety can maintain genetic stability under natural environments.

\section{High Mutation Efficiency}

The snapdragon "JI2" Tam3 mutation system has proved to be very efficient, mainly for two reasons. Firstly, 35 copies at most are expected to be movable among the total genomic 60 Tam 3 copies (Kishima et al. 1999). Secondly, every pod of the snapdragon can produce hundreds of tiny seeds. Usually, no more than ten pods are expected to be collected per plant (Figure 3). Theoretically, every pod is an independent mutant unit, so a few plants are sufficient to create an appropriate mutant population. The massive production of seeds will easily enable researchers to screen mutants with desirable phenotypes. This may be especially useful for screening abiotic stress tolerance mutation, in which many seeds are required due to high fatality under various stress treatments.
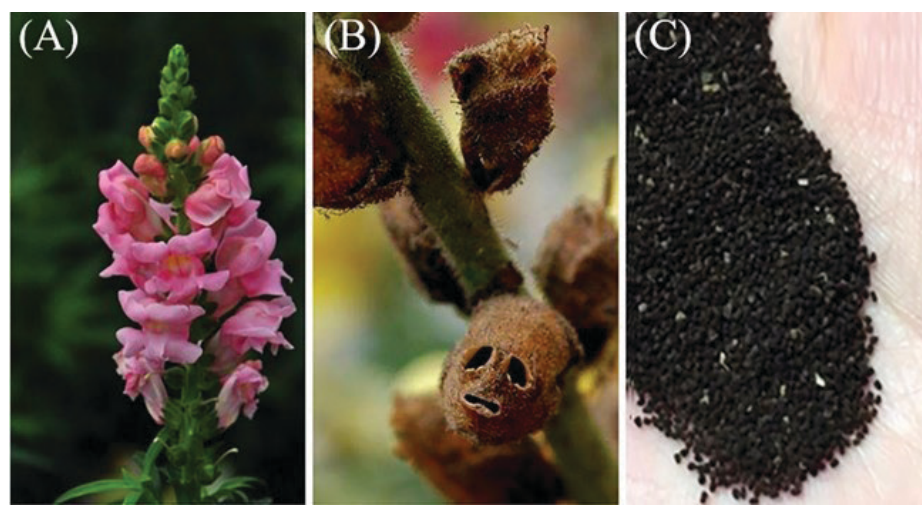

Figure 3. Snapdragon reproductive stages. (A) Flowers. (B) Pods. (C) Seeds.

Credits: Zhaoyuan Lian, UF/IFAS 
Figure 4 shows a variety of mutants, all of which were produced from only 5 original wild-type snapdragon "JI2" plants. Mutants with increased branching capacity may be valuable for nursery production of cut flowers, whereas the mutants with twisted branches and the red-leaf mutants exhibited higher aesthetic values. Potential isolation of a heat-tolerant mutant could significantly broaden the year-round use of snapdragon in Florida (Huo et al. 2018).

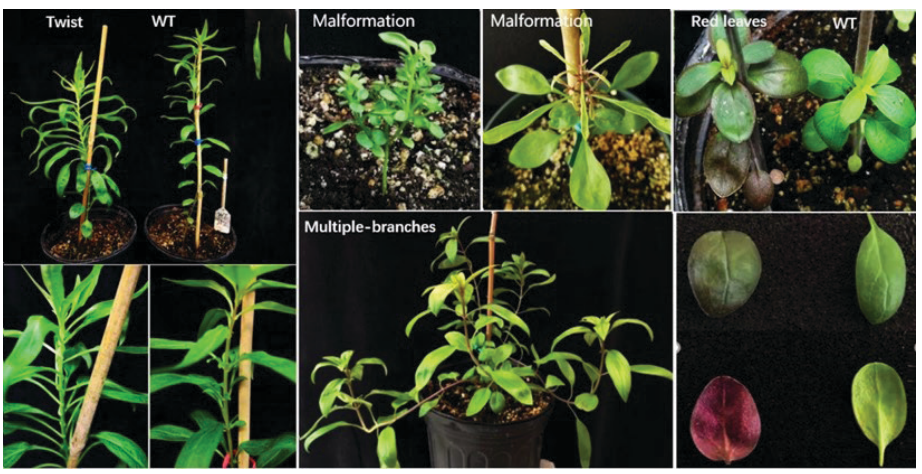

Figure 4. Mutants generated from Tam3 transposon transportation. Credits: Zhaoyuan Lian, UF/IFAS

\section{Photoperiod-Dependent Short-Life Cycles}

Snapdragon usually requires 5-6 months to go from the seed to seedling stage in the natural environment. However, its growth cycle period can be reduced to roughly 3.5 months if plants are grown in 22-24 hours of light. This longer photoperiod can promote snapdragon flower bud differentiation, significantly shorten and harden plant stems, and accelerate seed production (Figure 5).

\section{Easy Complementary Testing}

For functional characterization of candidate genes/mutations, one validation approach is to perform molecular complementation tests, in which a functional wild-type gene will be expressed to rescue the mutant phenotypes. This approach generally requires a time-consuming and complicated process that involves plasmid construction and genetic transformation. In our strategy, the mutants are cultivated at $15^{\circ} \mathrm{C}$ again to reactivate Tam 3 and allow it to "jump" out of the mutation locus to restore the gene function and phenotype. This is a simpler and more straightforward process. The excision of Tam 3 can be monitored by a general PCR with primers flanking the original insertion locus.

In summary, snapdragon offers endless possibilities for the plant breeder to develop new varieties. The many advantages to using the "JI2" mutagenesis system include operating convenience, non-GMO alternatives, photoperiod-dependent short-life cycles, and simpler complementary testing.

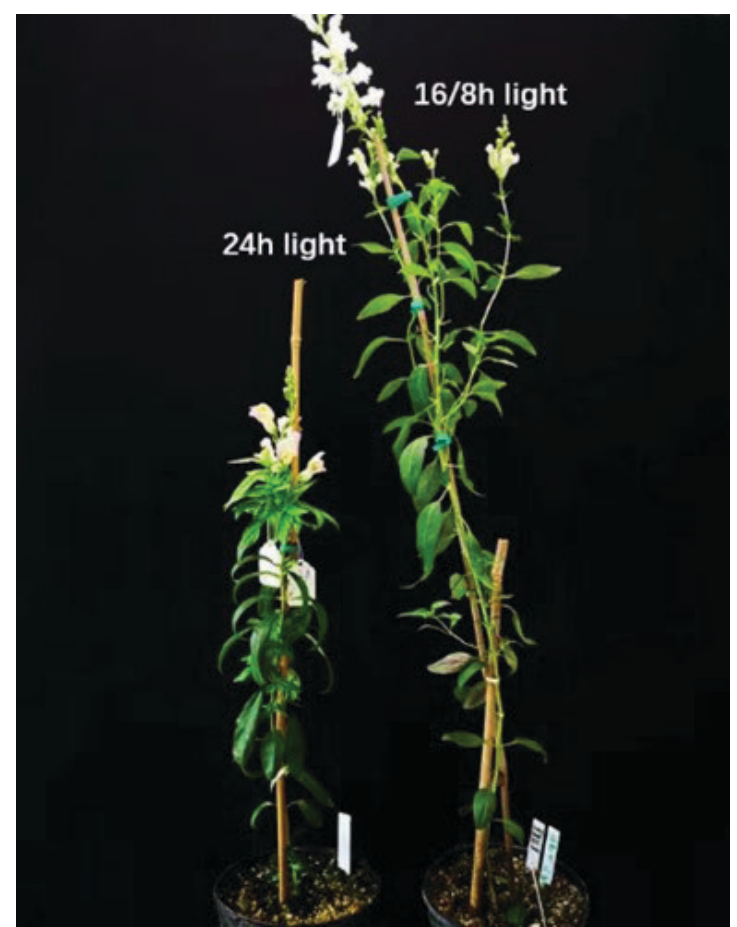

Figure 5. The comparison of snapdragon growth and development under photoperiodic treatments of 24 hours light and 16 hours light/8 hours dark.

Credits: Zhaoyuan Lian, UF/IFAS

\section{References}

Gilman, E. F., R. W. Klein, and G. Hansen. 2018. Antirrhinum majus Snapdragon. FPS-44. Gainesville: University of Florida Institute of Food and Agricultural Sciences. https:// edis.ifas.ufl.edu/fp044

Hashida, S. N., T. Uchiyama, C. Martin, Y. Kishima, Y. Sano, and T. Mikami. 2006. "The Temperature-Dependent Change in Methylation of the Antirrhinum Transposon Tam3 Is Controlled by the Activity of Its Transposase." Plant Cell 18(1): 104-118. doi: 10.1105/tpc.105.037655

Heqiang, H., and C. Jianjun. 2018. Planting and Propagation of Snapdragons in Florida. ENH1285. Gainesville: University of Florida Institute of Food and Agricultural Sciences. https://edis.ifas.ufl.edu/ep549

Jackson, D., K. Roberts, and C. Martin. 1992. “Temporal and Spatial Control of Expression of Anthocyanin Biosynthetic Genes in Developing Flowers of Antirrhinum majus." Plant J. 2(4): 425-434.

Kishima, Y., S. Yamashita, C. Martin, and T. Mikami. 1999. "Structural Conservation of the Transposon Tam3 Family in Antirrhinum majus and Estimation of the Number of Copies Able to Transpose." Plant Mol. Biol. 39(2): 299-308. 
USDA. 2016. "Floriculture Crops.” United States Depart-

ment of Agriculture. https://downloads.usda.library.cornell.

edu/usda-esmis/files/0p0966899/pz50gz655/8910jx14p/

FlorCrop-04-26-2016.pdf 